\title{
EVALUASI DAMPAK PENERAPAN AUTOMATED DISPENSING MACHINE TERHADAP DISPENSING ERROR DI FARMASI RAWAT JALAN INSTALASI FARMASI RUMAH SAKIT BETHESDA YOGYKARTA
}

\author{
Purwoadi Sujatno $^{1}$, Rizaldi Taslim Pinzon ${ }^{2 *}$, Andreasta Meliala ${ }^{3}$ \\ ${ }^{1}$ Student of Hospital Management Programe, Faculty of Medicine, Gadjah Mada University \\ ${ }^{2}$ Duta Wacana Christian University School of Medicine/Bethesda Hospital Yogyakarta \\ ${ }^{3}$ Hospital Management Programe, Faculty of Medicine, Gadjah Mada University
}

Received February 22, 2016; Accepted April 12, 2016

\begin{abstract}
Dispensing error is not uncommon in the medication proccess. Otomatisation of outpatient pharmacy services decrease the incidence of dispensing error, as well as improving the efficiency of picking, packing and labeling process. Since August 2014 an automated dispensing machine was installed in outpatient pharmascy Bethesda Hospital Yogyakarta, integrated with electronic prescribing and hospital information system. The objective of the study was to evaluate the impact of automated dispensing machine on the dispensing error at outpatient pharmacy Services using before and after study method. The procentage of drugs deliver by automated dispensing machine at the third and sixth month of implementation was $46 \%$ and 59\%. Failure mode and effeect analysis of dispensing process done before the implementation, and the integration with electronic prescription and hospital information system, as well as the development of smart pack is the key of successed. The average of medications picked after the implementation of automated dispensing machine was (37,915.33 $\pm 3,160.12)$, higher than before implementation $(36,812.67 \pm 2,890.81)$, but not significant. The average of dispensing error after implementation $(15,67 \pm 6,28)$ was reduced significantly $(p<0,05)$ than before $(50.33 \pm 34.47)$. The most frequent type of dispensing error were wrong quantity dispensed, wrong drug dispensed and wrong strength dispensed. The implementation of automated dispensing machine significantly reduce the incidence of dispensing error. Further investigaation needed to know the incidence of dispesning error cause by the machine and manual and factors that influenced.
\end{abstract}

Keywords: automated dispensing machine, dispensing error

\section{PENDAHULUAN}

Pelayanan kesehatan merupakan sistem kompleks yang ditandai dengan penggunaan teknologi tinggi, pelayanan multidisiplin dengan kebebasan dalam menjalankan profesi. Pelayanan kesehatan tidak dapat dilepaskan terhadap kemungkinan untuk membuat kesalahan atau melakukan pelayanan yang tidak sesuai dengan standar sehingga berpotensi atau bisa menyebabkan kejadian yang tidak diinginkan dan membahayakan pasien. Kegagalan untuk melaksanakan apa yang sudah direncanakan untuk mencapai tujuan yang sudah ditetapkan atau melaksanakan perencanaan yang tidak sesuai dengan tujuan yang akan dicapai (medical error) harus senantiasa diminimalkan dalam setiap upaya pelayanan kesehatan yang bermutu dan aman (Kohn et al., 2000).

Di Amerika Serikat dilaporkan 44.000 sampai 98.000 pasien meninggal setiap tahun akibat medical error. Dampak medical error sangat beragam mulai dari yang sangat ringan dan bisa pulih, sampai berat yang dapat menyebabkan kecacatan dan kematian. Medical error juga dapat menyebabkan bertambah parahnya penyakit sehingga lama dan biaya perawatan bertambah (Gyllensten, 2013).

*Corresponding author: Rizaldi Taslim Pinzon

Email: medidoc2002@yahoo.com 
Salah satu bentuk medical error yang paling sering terjadi adalah medication error-(Koo et al., 2012) melaporkan kejadian medication error sebesar $41,1 \%$, sebanyak $39,9 \%$ berpotensi menyebabkan kerugian serius dan sebagian besar (93,5\%) sebenarnya kejadian tersebut dapat dicegah. Penelitian di Australia didapatkan 190.000 pasien di rawat inap berkaitan dengan medication error per tahun dan menghabiskan biaya 660 juta dolar (Roughead and Semple, 2009).

Dispensing error merupakan permasalahan yang banyak terjadi dalam proses pengobatan. Flynn et al. (2003) melaporkan terjadinya 4 kesalahan untuk setiap 250 resep. Beso et al. (2005) melaporkan kejadian dispensing error sebesar $2 \%$ pada farmasi rumah sakit, sementara Sanchez (2013) melaporkan kejadian dispensing error 4,58 per 1000 item dispensed.

Institusi pelayanan kesehatan menyadari pentingnya melakukan perubahan dan menemukan solusi yang baik untuk menurunkan kejadian medication error. Untuk meningkatkan kualitas pelayanan, meminimalkan risiko kesalahan yang dibuat oleh faktor manusia, meningkatkan kapasitas pelayanan dan efisiensi maka pemanfaatan tehnologi informasi penting untuk dilakukan. Pemanfaatan robot untuk menggantikan peran manusia dalam proses pelayanan pengobatan sudah banyak digunakan. Salah satu yang digunakan adalah penerapan automated dispensing machine (Lakshmi et al., 2014).

Penelitian-penelitian yang berkaitan dengan penerapan automated dispensing machine masih terbatas dan kurang konklusif. Tsao et al. (2014) mendapatkan bahwa automated dispensing device memiliki potensi menurunkan medication error dan meningkatkan efisiensi yang terbatas. Potensi tersebut sangat tergantung pada institusi yang menerapkan dan seberapa baik diintegrasikan dengan proses distribusi obat. Ong et al. (2014) melakukan evaluasi terhadap dampak drug dispensing system terhadap keamanan dan efisiensi di farmasi rawat jalan mendapatkan bahwa penerapan drug dispensing system meningkatkan keamanan proses kerja farmasi dan meminimalkan kesalahan akibat faktor manusia dan meningkatkan efisiensi.
Sejak bulan Agustus 2014 di farmasi rawat jalan Instalasi Farmasi Rumah Sakit Bethesda mulai diterapkan automated dispensing machine. Tujuan utama penerapan automated dispensing machine ini adalah untuk menurunkan kejadian medication error dan mengurangi lama waktu tunggu pasien di farmasi rawat jalan. Penelitian ini bertujuan untuk mengevaluasi khususnya dampak penerapan automated dispensing machine terhadap kejadian medication error di farmasi rawat jalan.

\section{METODE PENELITIAN}

Jenis penelitian ini adalah eksperimental semu dengan rancangan penelitian before and after (pre and post test design). Penelitian ini dilakukan di farmasi rawat jalan Instalasi Farmasi Rumah Sakit Bethesda Yogyakarta pada bulan Juni-Juli 2015.

Subyek penelitian ini adalah resep pasien rawat jalan di Rumah Sakit Bethesda yang dilayani di farmasi rawat jalan pada bulan Pebruari sampai Juli 2014 dan pada bulan Oktober 2014 sampai Maret 2015. Kriteria inklusi adalah semua resep dari semua klinik. Kriteria eksklusi adalah semua resep racikan.

Variabel independen pada penelitian ini adalah penerapan automated dispensing machine. Variabel dependen pada penelitian ini adalah dispensing error. Variabel perancu pada penelitian ini adalah jumlah item obat dan asal poliklinik.

Luaran pada penelitian ini adalah dampak penerapan automated dispensing machine terhadap kejadian dispensing error yang dapat dicegah, yaitu yang terjadi sebelum obat keluar dari farmasi rawat jalan. Dispensing error yang ditemukan dan dilaporkan setelah obat keluar dari farmasi rawat jalan tidak digunakan sebagai luaran karena kejadiannya jarang dan kesulitan untuk mendapatkan data bahkan mungkin tidak didapatkan data tersebut.

Angka insiden dispensing error sebelum dan sesudah penerapan automated dispensing machine diperoleh dengan menghitung jumlah kejadian dispensing error dengan jumlah item obat yang dilayani pada periode tersebut. Analisa deskriptif terhadap jumlah, mean dan standar deviasi kejadian dispensing error. Perbedaan insidensi dispensing error sebelum dan sesudah penerapan 
automated dispensing machine dianalisis dengan menggunakan chi square test.

\section{HASIL DAN PEMBAHASAN \\ Penerapan Automated Dispensing Machine}

Automated dispensing machine mulai diterapkan di farmasi rawat jalan sejak bulan Agustus 2014, melayani resep permintaan obat dari seluruh klinik yang ada di rumah sakit. Untuk meminimalkan risiko kegagalan dalam implementasi alat ini, dilakukan disain ulang proses dispensing obat di farmasi rawat jalan menggunakan automated dispensing machine dengan menggunakan metode failure mode and effect analysis (FMEA). Alat ini diberi nama "Si Slamet" dengan harapan menjadi mesin penyelamat bagi farmasi rawat jalan untuk mengatasi 3 permasalahan utama pelayanan farmasi rawat jalan yaitu masalah medication error, waktu tunggu yang lama dan keterbatasan sumber daya manusia disamping keterbatasan ruang pelayanan.

Automated dispensing machine ini terdiri dari 2 bay, setiap bay terdiri dari 16 kolom dan 23 baris sehingga kapasitas alat ini adalah 730 chanel. Karena ada beberapa item obat yang lebar dan berat membutuhkan 2 chanel maka saat ini jumlah item obat yang dilayani oleh alat ini adalah 600 item obat. Pengisian ulang item obat ke dalam alat ini dilakukan dengan menggunakan sistem barcode untuk meminimalkan terjadinya kesalahan. Setiap item obat tablet yang dimasukkan ke dalam alat ini dikemas dalam suatu kemasan yang disebut "smart pack", yaitu kemasan obat yang berisi item obat dengan jumlah tertentu yang dibuat berdasarkan hasil evaluasi terhadap riwayat jumlah obat tersering yang diminta oleh dokter. Dokter membuat resep secara elektronik dengan memilih item obat dan jumlah obat yang bisa dilayani oleh automated dispensing machine. Evaluasi terhadap cakupan pelayanan alat ini yang dilakukan pada bulan ke-tiga dan ke-enam setelah penerapan alat ini mendapatkan cakupan sebesar $46 \%$ dan $59 \%$.

Peresepan elektronik di rawat jalan sudah dimulai sejak tahun 2009. Di setiap ruang periksa dokter disediakan komputer untuk membuat resep elektronik yang terintegrasi dengan sistem informasi rumah sakit. Automated dispensing machine juga terintegrasi dengan program peresepan elektronik dan sistem informasi rumah sakit.

Tabel 1. Karakteristik Dasar Subyek Penelitian dan Perbedaan Rerata Jumlah Item Obat dan Dispensing Error Per Bulan Sebelum dan Setelah Penerapan Automated Dispensing Machine

\begin{tabular}{lccc}
\hline & $\begin{array}{l}\text { Sebelum implementasi } \\
\text { automated dispensing } \\
\text { machine }\end{array}$ & $\begin{array}{l}\text { Setelah implementasi } \\
\text { automated dispensing } \\
\text { machine }\end{array}$ & $\mathrm{p}$ \\
\hline Asal resep & Semua klinik & Semua klinik & 0,542 \\
\hline $\begin{array}{l}\text { Rerata jumlah item } \\
\text { obat per bulan }\end{array}$ & $36.812,67 \pm 2.890,812$ & $37.915,33 \pm 3.160,122$ & 0,036 \\
\hline $\begin{array}{l}\text { Rerata dispensing } \\
\text { error per bulan }\end{array}$ & $50,33 \pm 34,477$ & $15,67 \pm 6,282$ & \\
\hline
\end{tabular}

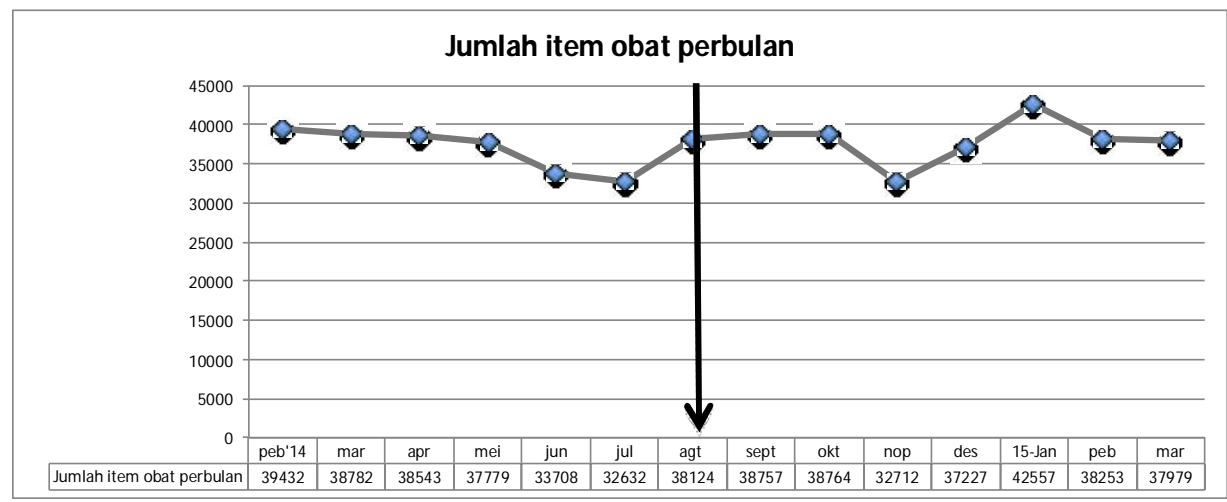

Gambar 1. Jumlah item obat perbulan 


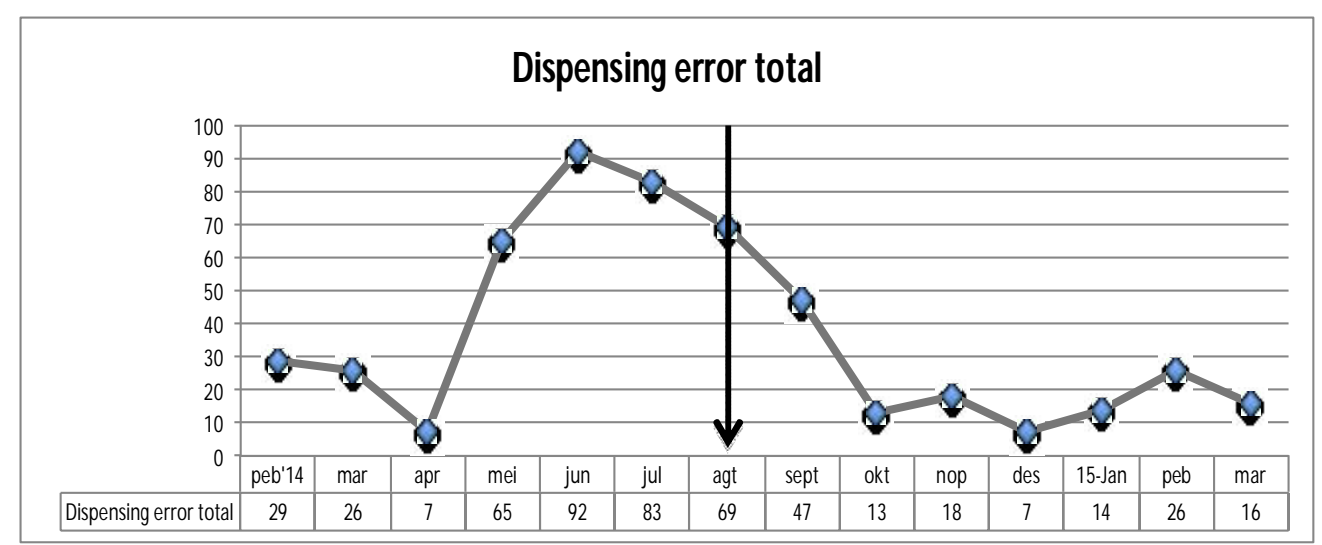

Gambar 2. Jumlah dispensing error perbulan

Tabel 2. Rerata Kejadian Dispensing Error Per Bulan Menurut Jenis dan Prosentase Dampak Perubahan Jenis Dispensing Error

\begin{tabular}{lccc}
\hline & $\begin{array}{c}\text { Sebelum implementasi } \\
\text { automated dispensing } \\
\text { machine (rerata per } \\
\text { bulan) }\end{array}$ & $\begin{array}{c}\text { Setelah implementasi } \\
\text { automated dispensing } \\
\text { machine (rerata per } \\
\text { bulan) }\end{array}$ & $\begin{array}{c}\% \\
\text { perubahan }\end{array}$ \\
\hline Wrong direction / warning on label & 3,167 & 0,5 & $-84,21$ \\
\hline Wrong dosage form dispensed & 2,167 & 1 & $-53,87$ \\
\hline Wrong dossage form on label & 0,167 & 0 & -100 \\
\hline Wrong drug dispensed & 12,167 & 2,5 & $-79,45$ \\
\hline Wrong drug name on label & 1 & 0,167 & $-83,33$ \\
\hline Wrong patient & 0,833 & 0,167 & -80 \\
\hline Wrong patient name on label & 0,333 & 0 & -100 \\
\hline Wrong quantity dispensed & 15,833 & 5,833 & $-63,16$ \\
\hline Wrong quantity on label & 0,5 & 0,167 & $-66,67$ \\
\hline Wrong strength dispensed & 6,667 & 3,667 & -45 \\
\hline Wrong strength on label & 1 & 0,333 & $-66,67$ \\
\hline Incorrect bag label & 0,167 & 0 & -100 \\
\hline Other error & 6,333 & 1,333 & $-78,94$ \\
\hline Total & 50,33 & 15,67 & $-69,78$ \\
\hline
\end{tabular}

\section{Evaluasi Penerapan Automated Dispensing Machine}

Pada penelitian ini item obat yang dilayani oleh farmasi rawat jalan sebelum dan sesudah penerapan automated dispensing machine berasal dari semua klinik rawat jalan, tidak ada penambahan klinik baru atau penutupan klinik selama periode penelitian. Rerata jumlah item obat yang dilayani di farmasi rawat jalan per bulan sebelum penerapan automated dispensing machine adalah 36.812,67 \pm 2.890,812, sedangkan setelah penerapan automated dispensing machine adalah 37.915,33 \pm $3.160,122$. Rerata jumlah item obat yang dilayani farmasi rawat jalan per bulan setelah implementasi automated dispensing machine lebih banyak sebesar 1.102,66 (Tabel 1). Gambar 1 menunjukkan jumlah item obat yang dilayani farmasi rawat jalan setiap bulan. Gambar 2 
menunjukkan kejadian dispensing error setiap bulan. Tabel 2 menunjukkan rerata kejadian dispensing error per bulan menurut jenis dan prosentase dampak perubahan jenis dispensing error.

Rerata jumlah item obat per bulan yang dilayani farmasi rawat jalan setelah penerapan automated dispensing machine lebih tinggi, tetapi dari analisis statistik beda rerata jumlah item obat perbulan sebelum dan setelah penerapan automated dispensing machine tidak berbeda secara bermakna ( $>0,05)$. Rerata kejadian dispensing error per bulan sebelum penerapan automated dispensing adalah 50,33 $\pm 34,477$, sedangkan rerata kejadian dispensing error setelah penerapan automated dispensing machine adalah 15,67 $\pm 6,282$. Rerata kejadian dispensing error setelah penerapan automated dispensing machine lebih rendah dan analisis statistik menunjukkan rerata kejadian dispensing error sebelum dan sesudah penerapan automated dispensing machine berbeda secara bermakna $(\mathrm{p}<0,05)$.

Penerapan automated dispensing machine pada penelitian ini berhasil meminimalkan terjadinya jenis dispensing error yaitu salah dosis di label, salah nama pasien di label, salah nama pada label (menurun 100\%). Selain itu kejadian jenis dispensing error yang juga menurun cukup besar adalah salah aturan pakai di label $(84,21 \%)$, salah nama obat di label $(83,33 \%)$, salah pasien $(80 \%)$, salah obat $(79,45 \%)$, salah jumlah obat $(66,67 \%)$ dan salah kekuatan atau dosis obat (45\%).

Item obat yang dilayani farmasi rawat jalan sebelum penerapan automated dispensing machine pada penelitian ini berasal dari klinik yang sama dengan setelah penerapan automated dispensing machine. Rerata jumlah item obat yang dilayani farmasi rawat jalan setelah penerapan automated dispensing machine lebih tinggi dibandingkan sebelum penerapan automated dispensing machine, tetapi perbedaan ini tidak bermakna secara statistik. Hal ini menunjukkan bahwa karakteristik dasar subyek penelitian tidak terdapat perbedaan antara sebelum dan sesudah penerapan automated dispensing machine.

Pada penelitian ini didapatkan rerata kejadian dispensing error per bulan setelah penerapan automated dispensing machine jauh lebih rendah. Penerapan automated dispensing machine mampu menurunkan kejadian dispensing error sebesar
69,78\%. Jenis dispensing error yang menurun banyak akibat penerapan automated dispensing machine adalah wrong drug dispensed dan wrong quantity dispensed.

Automated dispensing machine didisain antara lain untuk membuat proses filling terhadap setiap resep dan permintaan obat terpusat. Tujuan penggunaan automated dispensing machine dalam proses pelayanan obat terutama untuk peningkatan pelayanan terhadap pasien, memberikan pelayanan yang aman dan bermutu serta mengoptimalkan penggunaan sumber daya yang ada sehingga didapatkan pelayanan yang efisien.

Farmasi rawat jalan rumah sakit Bethesda mempunyai 3 permasalahan mendasar berkaitan dengan pelayanannya yaitu keterbatasan sumber daya manusia, kejadian medication error yang tinggi dan waktu tunggu yang lama. Hal ini sangat mempengaruhi kepuasan pelanggan terhadap pelayanan farmasi rawat jalan. Penambahan sumber daya manusia adalah hal yang mudah dilakukan tetapi merupakan investasi yang mahal, oleh sebab itu bukan merupakan prioritas pemecahan masalah. Beberapa upaya dilakukan untuk mengoptimalkan sumber daya manusia yang ada khususnya dalam upaya meminimalkan kejadian medication error. Pelatihan tentang keselamatan pasien diberikan kepada semua petugas farmasi. Untuk meningkatkan kewaspadaan petugas terhadap keselamatan pasien maka beberapa obat yang termasuk LASA (looks alike sound alike) ditampilkan di screen saver tiap-tiap komputer.

Sejak tahun 2009 mulai diterapkan peresepan elektronik di rawat jalan. Peresepan elektronik menyebabkan kemungkinan kesalahan pembacaan tulisan dokter berkurang. Ketika dokter menuliskan resep di komputer maka dia juga menulis label yang akan ditempelkan di obat sehingga apa yang tertulis di label benar-benar merupakan apa yang dokter minta. Karena label selalu akurat sesuai dengan yang diminta dalam resep maka kejadian transcription error tidak terjadi lagi.

Apakah upaya-upaya tersebut sukses menurunkan kejadian medication error? Ternyata tidak. Data tahun 2013 menunjukkan bahwa terdapat 584 kejadian medication error, paling banyak adalah kesalahan jumlah obat (157 kejadian) kemudian kesalahan dosis (116 kejadian) 
dan kesalahan jenis obat yang diberikan (90 kejadian). Pertumbuhan resep yang melebihi kapasitas produksi, resep yang menumpuk, beban kerja yang berat, kelelahan, tuntutan pasien membuat petugas tertekan dan merupakan akar masalah terjadinya medication error. Diperlukan langkah breakthrough yang secara signifikan dapat memberikan dampak perbaikan.

Setiap tahap proses pengobatan, yaitu tahap peresepan (prescribing), transcribing, dispensing dan administering, memiliki potensi untuk terjadi medication error. Faktor manusia sebagai penyebab terjadinya dispensing error tidak jarang terjadi. Automated dispensing machine dapat menurunkan kejadian dispensing error karena kemampuannya menggantikan peran petugas dalam proses filling untuk memenuhi permintaan setiap resep, mulai dari mengambil obat sesuai item obat, bentuk sediaan, kekuatan, jumlah obat dan labeling. Automated dispensing machine mampu menyediakan informasi yang akurat, mudah diakses dengan cepat untuk memenuhi permintaan pelayanan obat karena obat-obat tersebut siap tersedia untuk diakses dalam keadaan yang terkontrol keamanannya.

Kajian disain ulang proses dispensing farmasi rawat jalan menggunakan automated dispensing machine dengan metode FMEA dilakukan oleh suatu tim yang dibentuk oleh manajemen untuk meminimalkan kemungkinan kegagalan dalam penerapan alat ini. Hal ini merupakan salah satu faktor penting yang diambil manajemen dengan melakukan kajian mendalam yang bisa membuat berhasil ketika alat ini diimplementasikan. Dengan demikian semua faktor yang bisa menyebabkan kegagalan teridentifikasi dan jalan keluar untuk mengatasi faktor tersebut ditetapkan. Komitmen pimpinan dengan terlibat sejak awal dalam proses persiapan sampai implementasi dan dukungan penuh sangat penting dan membuat keberhasilan penerapan alat ini.

Manajemen memberi nama alat ini "Si Slamet" yang berarti selamat menunjukkan kuatnya perhatian manajemen terhadap masalah keselamatan dan keamanan dalam setiap proses pelayanan pasien. Keselamatan dan keamanan pelayanan merupakan hal mendasar yang dibutuhkan oleh setiap pasien. Dengan diberi nama "Si Slamet" bisa mengingatkan semua petugas, manajemen dan pasien untuk terus mengupayakan aspek keselamatan dan keamanan pelayanan.

Pada penelitian ini salah satu kunci sukses penurunan kejadian dispensing error adalah diintegrasikannya peresepan elektronik dengan sistem dispensing otomatis serta sistem informasi rumah sakit. Hal ini sesuai dengan penelitian yang dilakukan oleh Beard dan Smith (2013). Kesalahan dalam proses transcribing bisa berkurang dengan diterapkannya peresepan elektronik. Data umum pasien tidak perlu ditulis ulang karena sudah terintegrasi dengan sistem informasi rumah sakit. Tenaga farmasi cukup melakukan validasi terhadap resep yang masuk, tidak perlu menghabiskan banyak waktu untuk membaca tulisan dokter dalam resep yang sering tidak jelas atau konfirmasi kepada dokter kalau menjumpai kesulitan. Begitu proses validasi selesai dilakukan maka langsung mencetak billing dan label, automated dispensing machine langsung menjalankan tugasnya untuk proses filling. Itu sebabnya kesalahan dalam hal jenis obat, jumlah obat maupun kekuatan obat yang dilayankan sangat menurun.

Salah satu permasalahan yang juga dijumpai adalah bervariasinya jumlah obat yang diminta oleh dokter untuk setiap item obat yang diresepkan. Hal ini menyebabkan cakupan item obat yang dilayani oleh automated dispensing machine rendah karena sedikit yang siap tersedia di dalam alat. Ong et al. dalam penelitiannya mendapatkan bahwa rerata obat yang dilayani oleh automated dispensing machine hanya $21,067 \%$ meskipun alat tersebut sudah diimplementasikan selama 2 tahun. Untuk mengatasi hal ini maka dikembangkan smart pack, yaitu kemasankemasan yang dibuat berdasarkan hasil evaluasi terhadap item obat dan jumlah tiap item obat yang paling banyak diresepkan. Pengembangan smart pack ini merupakan salah satu inovasi yang dilakukan rumah sakit ini yang membedakan dengan penggunaan alat ini di tempat lain. Evaluasi pada bulan ke-tiga dan ke-enam setelah penerapan alat ini didapatkan bahwa obat yang dilayani masing-masing sebesar $46 \%$ dan $59 \%$. Hal ini kemungkinan juga disebabkan oleh penerapan peresepan olektronik yang sudah dilaksanakan selama lebih dari 5 tahun.

Pada penelitian ini rerata kejadian dispensing error perbulan selama 6 bulan sebelum dan 6 
bulan sesudah penerapan automated dispensing machine menurun dari rerata 50,33 $\pm 34,477$ perbulan menjadi 15,67 $\pm 6,282$ atau angka kejadian dispensing error (jumlah kejadian dispensing error per 100.000 item obat yang dilayani) dari 136,73 menjadi 41,32. Hal ini sesuai dengan penelitian yang dilakukan oleh Fitzpatick et al. (2005) yang melakukan evaluasi penerapan automated dispensing machine di farmasi rumah sakit, mendapatkan bahwa secara keseluruhan alat ini menurunkan angka kejadian dispensing error sebesar 104,9 kejadian per 100.000 item obat yang dilayani atau menurunkan $16 \%$ kejadian dibandingkan dengan sebelum penerapan alat tersebut. Pada penelitian tersebut kesalahan instruksi pada label bukannya turun tetapi justru semakin meningkat yaitu sebesar $35 \%$, disebabkan produksi label tersebut tidak terintegrasi dengan alat atau sistem informasi rumah sakit tetapi masih dilakukan oleh petugas. Oleh sebab itu total penurunan kejadian dispensing error setelah penerapan alat terebut hanya $16 \%$. Pada penelitian kami penurunan total kejadian dispensing error bisa mencapai 69,78\% karena sudah digunakannya peresepan elektronik sehingga kesalahan instruksi pada label sedikit terjadi dan faktor banyaknya item obat yang dilayani oleh automated dispensing machine (sampai 59\%) menjadi faktor yang berperan terhadap pencapaian hasil tersebut.

Pada penelitian ini didapatkan bahwa jenis dispensing error yang banyak terjadi adalah salah obat, salah jumlah obat, salah bentuk sediaan. Hal ini sesuai dengan penelitian yang dilakukan oleh James et al. (2009), melakukan evaluasi literature dari data elektronik dari tahun 1966 sampai tahun 2008 mendapatkan bahwa jenis dispensing error yang paling umum terjadi adalah salah obat, salah dosis dan salah jumlah atau bentuk sediaan. Beban kerja yang tinggi, adanya gangguan ketika sedang menjalankan tugas (interupsi) dan pencahayaan di tempat kerja yang tidak memadai berperan meningkatkan kejadian dispensing error. Sanchez (2013) pada penelitiannya mendapatkan jenis dispensing error yang paling sering terjadi adalah salah dosis diikuti salah jumlah dan salah obat.

Penerapan automated dispensing machine pada penelitian ini berhasil meminimalkan terjadinya jenis dispensing error yaitu salah dosis di label, salah nama pasien di label, salah nama pada label (menurun 100\%). Selain itu kejadian jenis dispensing error yang juga menurun cukup besar adalah salah aturan pakai di label $(84,21 \%)$, salah nama obat di label $(83,33 \%)$, salah pasien $(80 \%)$, salah obat $(79,45 \%)$, salah jumlah obat $(66,67 \%)$ dan salah kekuatan atau dosis obat (45\%). Dampak penerapan automated dispensing machine terhadap penurunan jenis dispensing error pada penelitian ini jauh lebih besar dibandingkan penelitian dari Fitzpatrick et al. yang endapatkan penurunan sebesar $45 \%$ yaitu pada penurunan kejadian dispensing error salah kekuatan atau dosis obat. Hal ini disebabkan karena sudah terintegrasinya automated dispensing machine dengan peresepan elektronik dan sistem informasi rumah sakit. Faktor dukungan para klinisi yang besar dalam menggunakan resep elektronik dan semakin banyaknya cakupan item obat yang dilayani oleh alat tersebut menjadi kunci keberhasilan penerapan automated dispensing machine ini dalam menurunkan angka kejadian dispensing error.

\section{KESIMPULAN}

Penerapan automated dispensing machine menurunkan kejadian dispensing error secara bermakna.

Perlu dikembangkan lebih lanjut penerapan automated dispensing machine tidak hanya di farmasi rawat jalan tetapi juga di farmasi rawat inap. Perlu penelitian lebih lanjut yang lebih rinci meneliti dan memisahkan kejadian dispensing error yang disebabkan oleh proses filling manual dan otomatis serta faktor-faktor apa yang mempengaruhi sehingga bisa diambil langkah-langkah strategis untuk lebih meminimalkan terjadinya dispensing error.

\section{DAFTAR PUSTAKA}

Beard, R.J., Smith, P., 2013. Integrated electronic prescribing and robotic dispensing: a case study. Springer Plus, 2, 295.

Beso, A., Franklin, B.D., Barber, N., 2005. The Frequency and Potential Causes of Dispensing Errors in A Hospital Pharmacy. Pharm World Sci, 27,182-90.

Fitzpatrick, R., Cooke, P., Southall, C., Kauldhar, K., Waters, P., 2005. Evaluation of an automated dispensing system in a hospital pharmacy dispensary. The Pharmaceutical Journal, 275, 763-5.

Flynn, E.A., Barker, K.N., Carnahan, B.J., 2003. National Observational Study of Prescription 
Dispensing Accuracy and Safety in 50 Pharmacies. Journal of the American Pharmaceutical Association, 43,2.

Gyllensten, G., Rehnberg, C., Jonsson, A.K., Petzold, M., Carlsten, A., Sundell, K.A., 2013. Cost of illness of patient-reported adverse drug events: a population-based cross-sectional survey. BMJ Open, 3:e002574.

James, K.L., Barlow, D., McArtney, R., Hiom, S., Robert, D., Whittlesea, C., 2009. Incidence, type and causes of dispensing error: a review of the literature. International Journal of Pharmacy Practice, 17, 9-30.

Kohn, L.T., Corrigan, J., Donaldson, M.S., 2000. To err is human: building a safer health care system. National Academy of Sciences. Washington DC.

Koo, E.M., Lee, W.K., Sararaks, S., Samad, A.A., Liew, S.M., Cheong, A.T., Ibrahim, M.Y., Su, S.H.C., Hanafiah, A.N.M., Maskon, K., Ismail, R., Hamid, M.A., 2012. Medical error in primary care clinics - a cross sectional study. BMC Family Practice, 13,127.

Lakshmi, T.T., Keerthi, P., Debarshi, D., Niranjan, B.M., 2014. Recent trends in the usage of robotics in pharmacy. Indian Journal of Research in Pharmacy and Biotechnology, 2(1),1038-43

Ong, P.Y.S., Chen, L.L., Wong, J.A., Gunawan, Y., Goh, W.J., Tan, M.C., Lee, S.B., 2014. Evaluating the Impact of Drug Dispensing System on the Safety and Efficiency in a Singapore Outpatient Pharmacy. Innovation in pharmacy, 5(3), 169

Roughead, E.E., Semple, S.J., 2009. Medication safety in acute care in Australia: where are we now? Part I: review of the extent and causes of medication problems 2002-2008. Australia and New Zealand Health Policy, 6,18.

Sanchez, A.M.M., 2013. Incidence, type and causes of dispensing errors: a study from the community pharmacy. African Journal of Pharmacy and Pharmacology, 7(13),715-20.

Tsao, N.W., Lo, C., Babich, M., Shah, K., Bansback, N.J., 2014. Decentralized automated dispensing devices: systematic review of clinical and economic impacts in hospital. CJHP, 67(2), 138-48. 